\title{
Hasil Supervisi Mutu Pendidikan pada Sekolah Model SMK Negeri 1 Pujut Tahun 2020
}

\author{
H. Jayadi Putra \\ Pengawas SMK Kabupaten Lombok Tengah - Provinsi NTB \\ Corresponding Author. Email: hajijayadi1970@gmail.com
}

\begin{abstract}
This study aims to provide assistance to improve quality in accordance with national education standards or to exceed national education standards so that the formation of a quality culture in SMK Negeri 1 Pujut. This research was conducted using descriptive methods. The stages in the implementation of quality supervision, namely; (1) Mapping and validating school conditions, (2) Formulating future recommendations for solutions, (3) Assisting in implementing solutions, and (4) Evaluating their impacts and changes. The data analysis technique of this research is using descriptive analysis. The results of this study include; (1) The understanding of the quality standards at SMKN 1 Pujut is already good, indicated by the quality report cards that have reached SNP 4 with an achievement value of 5.74; (2) Implementation of the Internal Quality Assurance System (SPMI) at SMKN 1 Pujut has been carried out well, starting from quality mapping, planning, implementation, evaluation and standard setting; (3) Implementation of K13 at SMKN 1 Pujut is in accordance with the provisions; (4) Strengthening Character Education (PPK) at SMKN 1 Pujut has been running well, indicated by the results of PPK report cards reaching 6.48 towards SNP 4; (5) The School Literacy Movement (GLS) at SMKN 1 Pujut has achieved SNP with a score of 6.69; and (6) Implementation of UKS at SMKN 1 Pujut reaches 5.8 towards SNP 4.
\end{abstract}

Article History

Received: 18-02-2021

Revised: 12-03-2021

Published: 04-04-2021

Key Words:

Quality Supervision,

Education, Model

Schools.

\begin{abstract}
Abstrak: Penelitian ini bertujuan untuk melakukan pendampingan untuk Sejarah Artikel peningkatan mutu sesuai dengan standar nasional pendidikan atau melampaui Diterima: 18-02-2021 standar nasional pendidikan sehingga terbentuknya budaya mutu di SMK Negeri 1 Direvisi: 12-03-2021 Pujut. Penelitian ini dilakukan dengan menggunakan metode deskriptif. Tahapan Diterbitkan: 04-04-2021 dalam pelaksanaan supervisi mutu yaitu; (1) Pemetaan dan validasi kondisi sekolah, (2) Penyusunan rekomendasi solusi ke depan, (3) Pendampingan pelaksanaan solusi, dan (4) Evaluasi dampak dan perubahannya. Teknik analisis data penelitian ini menggunakan analisis deskriptif. Hasil penelitian ini antara lain; Kata Kunci: (1) Pemahaman tentang Standar Mutu di SMKN 1 Pujut sudah baik ditandai Supervisi Mutu, dengan hasil raport mutu sudah menuju SNP 4 dengan nilai capaian 5,74; (2) Pendidikan, Sekolah Penerapan Sistem Penjaminan Mutu Internal (SPMI) di SMKN 1 Pujut sudah Model. terlaksana dengan baik mulai dari pemetaan mutu, perencanaan, pelaksanaan, evaluasi dan penetapan standar; (3) Implementasi K13 di SMKN 1 Pujut sudah sesuai dengan ketentuan; (4) Penguatan Pendidikan Karakter (PPK) di SMKN 1 Pujut sudah berjalan dengan baik ditandai dengan hasil raport PPK mencapai 6.48 menuju SNP 4; (5) Gerakan Literasi Sekolah (GLS) di SMKN 1 Pujut sudah mencapai SNP dengan nilai 6.69; dan (6) Pelaksanaan UKS di SMKN 1 Pujut mencapai 5.8 menuju SNP 4.
\end{abstract}

How to Cite: Putra, H. (2021). Hasil Supervisi Mutu Pendidikan pada Sekolah Model SMK Negeri 1 Pujut Tahun 2020. Jurnal Paedagogy, 8(2). doi:https://doi.org/10.33394/jp.v8i2.3522

\section{Pendahuluan}

Sistem pendidikan nasional yang didefinisikan dalam Undang-undang Nomor 20 Tahun 2003 adalah keseluruhan komponen pendidikan yang saling terkait secara terpadu untuk mencapai tujuan pendidikan nasional yaitu untuk mengembangkan kemampuan serta 
meningkatkan mutu kehidupan dan martabat manusia Indonesia. Dalam PP Nomor 13 Tahun 2015 Tentang Standar Nasional Pendidikan, satuan pendidikan diwajibkan untuk melaksanakan penjaminan mutu pendidikan. Penjaminan mutu pendidikan ini bertujuan untuk memenuhi atau melampaui Standar Nasional Pendidikan. Setiap satuan pendidikan beserta seluruh komponen di dalamnya memiliki tanggungjawab dalam peningkatan dan penjaminan mutu pendidikan.

Sistem penjaminan mutu pendidikan adalah kegiatan sistemik dan terpadu oleh satuan pendidikan atau sekolah, penyelenggara program pendidikan, pemerintah daerah, pemerintah pusat, dan masyarakat untuk memperbaiki mutu pendidikan (Prayoga, 2020; Yuniati, 2019; Rusdi, 2020; Supatni, 2017). Penjaminan mutu pendidikan diperlukan: (1) mutu pendidikan bervariasi antarsekolah/ madrasah, antardaerah; (2) setiap siswa berhak memperoleh layanan pendidikan bermutu; (3) perbaikan mutu sekolah/madrasah berkelanjutan sebagai kebutuhan; dan (4) mutu pendidikan yang rendah akan menyebabkan daya saing SDM rendah (Suginam, 2019; Purnamaraya, 2019; Rusmiarsi, 2017).

Peningkatan mutu di satuan pendidikan tidak dapat berjalan dengan baik tanpa adanya budaya mutu pada seluruh komponen sekolah. Untuk peningkatan mutu sekolah secara utuh dibutuhkan pendekatan yang melibatkan seluruh komponen sekolah (whole school approach) agar seluruh komponen sekolah bersama-sama memiliki budaya mutu. Agar penjaminan mutu dapat berjalan dengan baik, pada jenjang pendidikan dasar dan menengah telah dikembangkan Sistem Penjaminan Mutu Pendidikan Dasar dan Menengah (SPMPDM) yang terdiri atas Sistem Penjaminan Mutu Internal (SPMI) dan Sistem Penjaminan Mutu Eksternal (SPME). Sistem Penjaminan Mutu Internal pada satuan pendidikan dijalankan oleh seluruh komponen dalam satuan pendidikan. SPMI mencakup seluruh aspek penyelenggaraan pendidikan dengan memanfaatkan berbagai sumber daya untuk mencapai Standar Nasional Pendidikan. SPMI dievaluasi dan dikembangkan secara berkelanjutan oleh satuan pendidikan. SPMI juga ditetapkan oleh satuan pendidikan dan dituangkan dalam pedoman pengelolaan satuan pendidikan serta disosialisasikan kepada pemangku kepentingan satuan pendidikan.

Agar pelaksanaan SPMI dapat dilakukan oleh seluruh satuan pendidikan dengan optimal, perlu dilakukan kegiatan supervisi mutu pendidikan berkelanjutan oleh supervisor ke setiap satuan pendidikan dasar dan menengah. Kegiatan supervisi mutu pendidikan mencakup supervisi dalam integrasi penerapan Kurikulum 2013 (K13), Penguatan Pendidikan Karakter (PPK), Gerakan Literasi Sekolah (GLS), dan aspek mutu lainnya dalamproses pembelajaran dan manajemen sekolah sesuai Standar Nasional Pendidikan. Hasil Supervisi ini disusun sebagai bentuk akuntabilitas pelaksanaan supervisi mutu pendidikan di sekolah (SMK Negeri 1 Pujut) termasuk supervisi dalam integrasi kurikulum 2013 (K13), penguatan pendidikan karakter, gerakan literasi sekolah, dan aspek mutu pendidikan lainnya dalam implementasi Sistem Penjaminan Mutu Internal (SPMI) sesuai Standar Nasional Pendidikan.

Supervisi mutu secara umum bertujuan untuk melakukan pendampingan untuk peningkatan mutu sesuai dengan standar nasional pendidikan atau melampaui standar nasional pendidikan sehingga terbentuknya budaya mutu di satuan pendidikan. Secara khusus supervisi mutu bertujuan sebagai berikut:

1) Peningkatan integrasi pemahaman standar nasional pendidikan di satuan pendidikan.

2) Peningkatan integrasi pelaksanaan SPMI di satuan pendidikan.

3) Peningkatan integrasi implementasi K13 pada satuan pendidikan

4) Peningkatan integrasi penguatan pendidikan karakter di satuan pendidikan.

5) Peningkatan integrasi gerakan literasi sekolah di satuan pendidikan. 
6) Peningkatan integrasi pelaksanaan UKS di satuan pendidikan.

Adapun penelitian ini bertujuan untuk melakukan pendampingan untuk peningkatan mutu sesuai dengan standar nasional pendidikan atau melampaui standar nasional pendidikan sehingga terbentuknya budaya mutu di SMK Negeri 1 Pujut.

\section{Metode Penelitian}

Metode yang digunakan dalam penelitian ini metode deskriptif. Penelitian ini dilaksanakan di SMK Negeri 1 Pujut Kabupaten Lombok Tengah. Sumber data penelitian ini antara lain Kepala Sekolah, Wakil Kepala Sekolah Bidang Kurikulum, Ketua TPMPS (Amsah,S.Pd), Wk.Ketua TMPS (Wirame, S.Pd.), Sekretaris TPMPS (Suherman, S.Pd), Bendahara TPMPS (Yani Surya Sakiman Hadi, S.Pd), Anggota TPMPS (Lalu Wirahadi Kusuma, S.P. ), Anggota TPMPS (Mandah, S.Pd), Guru Matematika ( Ibu Andi Lutfi, S.Pd.) dan Guru Bahasa Ingris ( Adi Punawarman, S.Pd.), dan beberapa orang siswa.

Tahapan dalam pelaksanaan supervisi mutu yang dilakukan yaitu; (1) Pemetaan dan validasi kondisi sekolah, (2) Penyusunan rekomendasi solusi ke depan, (3) Pendampingan pelaksanaan solusi, dan (4) Evaluasi dampak dan perubahannya. Aktivitas pengamatan dilaksanakan dengan berbagai kegiatan seperti; (1) Analisis dokumen dilaksanakan untuk menganalisis berbagai dokumen yang diperlukan untuk mendapatkan data yang autentik terkait dengan objek yang disupervisi (SPMI, Manajemen Sekolah, Proses Pembelajaran, Dampak Kompetensi Lulusan) yang mengintegrasikan GLS, PPK, dan UKS. (2) Wawancara dilaksanakan untuk mendeskripsikan data yang bersifat kuantitatif maupun kualitatif. (3) Observasi lapangan dilaksanakan untuk mengecek keabsahan atau validitas data yang bersumber dari dokumen ataupun informasi kualitatif/ kuantitatif pada wawancara yang dilaksanakan. (4) Diskusi terpumpun dilaksanakan untuk menyamakan persepsi dan kesepahaman tentang data yang bersumber dari dokumen ataupun informasi kualitatif/ kuantitatif pada wawancara yang dilaksanakan. Dokumen yang disupervisi yaitu:

(1) Rapor mutu, yaitu rapor yang mempresentasikan capain/ pemenuhan mutu 8 standar nasional pendidikan.

(2) Rapor mutu Gerakan Literasi sekolah, yaitu rapor capaian/ pemenuhan integrasi GLS.

(3) Rapor Penguatan Pendidikan Karakter, yaitu rapor capaian/ pemenuhan integrasi PPK.

(4) Rapor Usaha Kesehatan Sekolah, yaitu rapor capaian/ pemenuhan integrasi UKS.

(5) Dokumen KTSP K13 (Buku 1, Buku 2, dan Buku 3) untuk mengetahui konsistensi dokumen yang mengintegrasi GLS, PPK, dan UKS.

(6) Buku indikator mutu standar nasional pendidikan

(7) Dokumen Pelaksanaan SPMI

(8) Program GLS, Laporan integrasi GLS

(9) Program PPK, Laporan integrasi PPK

(10) Program UKS, Laporan integrasi UKS

Adapun bentuk dokumentasi hasil pengamatan penelitian ini yakni;

(1) Hasil Pengamatan, Analisis Hasil Pengamatan, Solusi, Aktivitas pendampingan, foto pelaksanaan supervisi pemahaman standar mutu dan penerapan SPMI

(2) Hasil Pengamatan, Analisis Hasil Pengamatan, Solusi, Aktivitas pendampingan foto pelaksanaan supervisi Manajemen sekolah

(3) Hasil Pengamatan, Analisis Hasil Pengamatan, Solusi, Aktivitas pendampingan foto pelaksanaan supervisi Proses Pembelajaran 
(4) Hasil Pengamatan, Analisis Hasil Pengamatan, Solusi, Aktivitas pendampingan, foto pelaksanaan supervisi dampak penjaminan mutu pada peningkatan kompetensi lulusan.

Selanjutnya teknik analisis data yang digunakan untuk mengolah data penelitian ini adalah dengan analisis deskriptif.

\section{Hasil Penelitian dan Pembahasan}

Hasil penelitian ini memaparkan data terkait; pemahaman standar mutu dan penerapan sistem penjaminan mutu internal (SPMI), supervisi penjaminan mutu pelaksanaan manajemen sekolah, dan supervisi dampak penjaminan mutu pada peningkatan kompetensi lulusan yang dijabarkan dalam bentuk tabel berikut ini.

\section{Pemahaman Standar Mutu \& Penerapan Sistem Penjaminan Mutu Internal (SPMI)}

\begin{tabular}{|c|c|c|c|}
\hline Hasil pengamatan & Analisis & Solusi & $\begin{array}{c}\text { Aktifitas } \\
\text { Pendampingan }\end{array}$ \\
\hline $\begin{array}{l}\text { Pemahaman Standar } \\
\text { 1. Sekolah memiliki } \\
\text { dokumen standar } \\
\text { 2. } \\
\text { sekolah sudah } \\
\text { melakukan EDS } \\
\text { 3. } \\
\text { sekolah belum } \\
\text { melakukan } \\
\text { sosialisasi tentang } \\
\text { SMPI ke stake } \\
\text { holder }\end{array}$ & $\begin{array}{l}\text { Hal yang sudah } \\
\text { baik: } \\
\text { 1. Sekolah memiliki } \\
\quad \text { dokumen standar } \\
\text { 2. Sekolah telah } \\
\quad \text { melakukan EDS } \\
\\
\text { Hal yang Belum } \\
\text { baik: } \\
\text { sekolah belum } \\
\text { melakukan } \\
\text { sosialisasi tentang } \\
\text { SMPI ke stake } \\
\text { holder }\end{array}$ & $\begin{array}{l}\text { Pengembangan: } \\
\text { 1. Sekolah } \\
\text { melaksanakan bedah } \\
\text { standar } \\
\text { 2. Sekolah mengundang } \\
\text { narasumber untuk } \\
\text { memberikan } \\
\text { pendalamanan ttg } \\
\text { standar } \\
\text { Perbaikan : } \\
\text { Sekolah hendaknya } \\
\text { melukan sosialisasi } \\
\text { keseluruh pemangku } \\
\text { kepentingan }\end{array}$ & 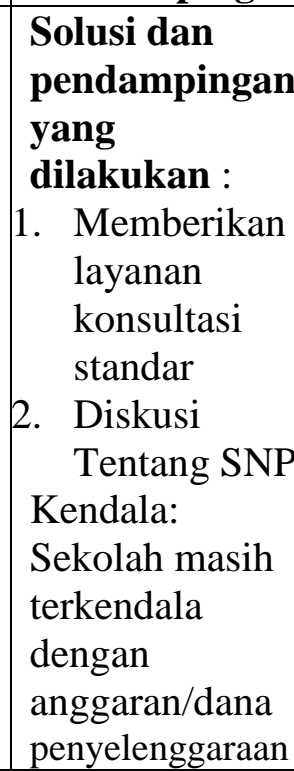 \\
\hline $\begin{array}{l}\text { Pelaksanaan SPMI } \\
\text { 1. Sekolah telah } \\
\text { melakukan anlisis } \\
\text { pemetaanmutu } \\
\text { 2. sekolah telah } \\
\text { membuat perencanaan } \\
\text { peningkatan mutu } \\
\text { 3. sekolah telah } \\
\text { melaksankan evaluasi } \\
\text { pelaksanaan kegiatan } \\
\text { 4. sekolah belum } \\
\text { membuat penetapan } \\
\text { standar mutu }\end{array}$ & $\begin{array}{l}\text { Hal yang sudah } \\
\text { baik: } \\
\text { 1. Sekolah telah } \\
\text { melakukan anlisis } \\
\text { pemetaanmutu } \\
\text { 2. sekolah telah } \\
\text { membuat } \\
\text { perencanaan } \\
\text { peningkatan mutu } \\
\text { 3. sekolah telah } \\
\text { melaksankan } \\
\text { evaluasi pelaksanaan } \\
\text { kegiatan } \\
\text { Hal yang Belum } \\
\text { baik: }\end{array}$ & $\begin{array}{l}\text { Alternatif solusi: } \\
\text { Sekolah mlakukan } \\
\text { diskusi tentang } \\
\text { perencaan untuk menjadi } \\
\text { lebih baik } \\
\text { Perbaikan: } \\
\text { Sekolah akan } \\
\text { melaksanakan penetapan } \\
\text { Standar Mutu }\end{array}$ & 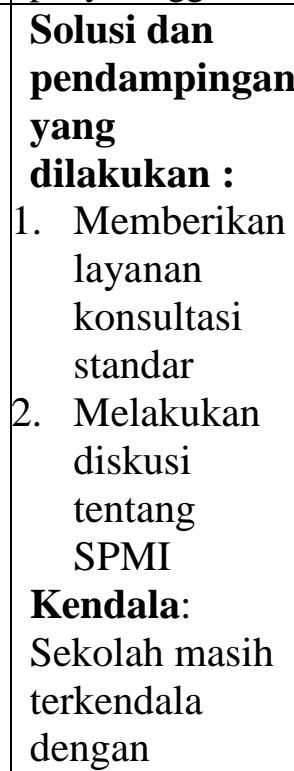 \\
\hline
\end{tabular}




\begin{tabular}{|c|c|c|c|}
\hline & $\begin{array}{l}\text { sekolah belum } \\
\text { membuat penetapan } \\
\text { stndar mutu }\end{array}$ & & $\begin{array}{l}\text { anggaran/dana } \\
\text { penyelenggaraan }\end{array}$ \\
\hline $\begin{array}{l}\text { Pelaksanaan PPK } \\
\text { 1. Pemilihan } \\
\text { ektrakurikuler yang } \\
\text { bergam untuk } \\
\text { menumbuhkan nilai } \\
\text { PPK sudah } \\
\text { sangabaik } \\
\text { 2. Pengembangan } \\
\text { potensi peserta didik } \\
\text { melalui keteladanan } \\
\text { kepala sekolah, } \\
\text { guru, dan tenaga } \\
\text { kependidikan sudah } \\
\text { sangat baik } \\
\text { 3. Pemanfaatan TIK } \\
\text { dan lingkungan } \\
\text { sebagai suber } \\
\text { belajar belum } \\
\text { optimal }\end{array}$ & $\begin{array}{l}\text { Hal yang sudah } \\
\text { baik : } \\
\text { 1. Pemilihan } \\
\text { ektrakurikuler yang } \\
\text { bergam untuk } \\
\text { menumbuhkan nilai } \\
\text { PPK sudah } \\
\text { sangabaik } \\
\text { 2. Pengembangan } \\
\text { potensi peserta didik } \\
\text { melalui keteladanan } \\
\text { kepala sekolah, } \\
\text { guru,dan tenaga } \\
\text { kependidikan sudah } \\
\text { sangat baik } \\
\text { Hal yang belum } \\
\text { baik : } \\
\text { Pemanfaatan TIK } \\
\text { dan lingkungan } \\
\text { sebagai suber belajar } \\
\text { belum optimal }\end{array}$ & $\begin{array}{l}\text { Pengembangan : } \\
\text { Sekolah dapat } \\
\text { menambah jenis kegiatan } \\
\text { ektra } \\
\text { Perbaikan : } \\
\text { Sekolah dapat } \\
\text { melakukan IHT tentang } \\
\text { pemanfaatan TIK }\end{array}$ & 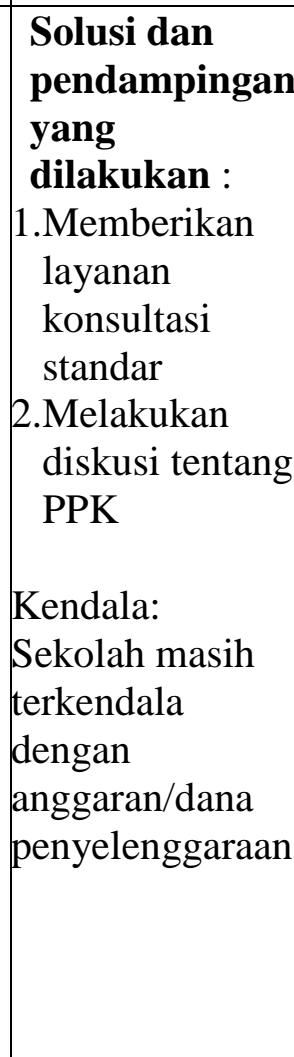 \\
\hline $\begin{array}{l}\text { Pelaksanaan GLS } \\
\text { 1. Adanya kegiatan } \\
\text { ekstra kurikuler } \\
\text { sekolah (PMR, } \\
\text { Beladiri, Pramuka) } \\
\text { 2. Belum selurh Siswa } \\
\text { mengunjungi } \\
\text { perepustakaan }\end{array}$ & $\begin{array}{l}\text { Hal yang sudah } \\
\text { baik: } \\
\text { Adanya kegiatan } \\
\text { ekstra kurikuler } \\
\text { sekolah (PMR, } \\
\text { Beladiri, Pramuka) } \\
\text { Hal yang belum } \\
\text { baik: } \\
\text { Siswa yang } \\
\text { mengunjungi } \\
\text { perpustakaan belum } \\
\text { seluruhnya (rata2 } \\
\text { per hari sekitar 20- } \\
30 \text { siswa }\end{array}$ & $\begin{array}{l}\text { Pengembangan: } \\
\text { Sekolah hendaknya } \\
\text { menambah kegiatan } \\
\text { ektrakurikuler } \\
\text { Perbaikan: } \\
\text { 1. Menyediakan sudut } \\
\text { kelas untuk kegiatan } \\
\text { membaca } \\
\text { 2. Menambah buku- } \\
\text { buku di perpustakaan }\end{array}$ & $\begin{array}{l}\text { Solusi dan } \\
\text { pendampingan } \\
\text { yang } \\
\text { dilakukan: } \\
\text { Melaksanakan } \\
\text { diskusi dan } \\
\text { konsultasi } \\
\text { dengan ketua } \\
\text { TPMPS terkait } \\
\text { dengan } \\
\text { keberadaan } \\
\text { kegiatan } \\
\text { sekolah } \\
\text { Kendala- } \\
\text { kendala: } \\
\text { Sekolah masih } \\
\text { terkendala } \\
\text { dengan } \\
\text { anggaran/dana } \\
\text { penyelenggaraan }\end{array}$ \\
\hline $\begin{array}{l}\text { Pelaksanaan UKS } \\
\text { 1. Adanya obat- }\end{array}$ & $\begin{array}{l}\text { Hal yang sudah } \\
\text { baik: }\end{array}$ & $\begin{array}{l}\text { Pengembangan: } \\
\text { Sekolah }\end{array}$ & $\begin{array}{l}\text { Solusi dan } \\
\text { pendampingan }\end{array}$ \\
\hline
\end{tabular}


abatan untuk UKS

2. Belum memiliki ruang UKS

3. WC/Toilet belum bersih

4. WC/Toilet siswa masih kurang (terdapat 10 ruang toilet)
Adanya obat-abatan untuk UKS

\section{Hal yang belum baik:}

1. Belum memiliki ruang UKS

2. WC/Toilet belum bersih

3. WC/Toilet siswa masih kurang (terdapat 10 ruang toilet)

\section{memprogramkan} penambahan sarana dan prasaran UKS

\section{Perbaikan:}

1. Membuat ruang UKS

2. Menyediakan tempat cuci tangan di depan kelas yang

dilakukan :

1. Memberikan layanan konsultasi standar

2. Melakukan diskusi tentang PPK

\section{Supervisi Penjaminan Mutu Pelaksanaan Manajemen Sekolah}

\begin{tabular}{|c|c|c|c|}
\hline $\begin{array}{c}\text { Catatan Hasil } \\
\text { Pengamatan }\end{array}$ & Analisis Hasil Pengamatan & $\begin{array}{c}\text { Solusi / } \\
\text { Tindaklanjut }\end{array}$ & $\begin{array}{c}\text { Aktivitas } \\
\text { Pendampingan }\end{array}$ \\
\hline $\begin{array}{l}\text { 1. Sekolah sudah } \\
\text { melakukan jejaring } \\
\text { pendidikan dengan } \\
\text { berbagai pihak } \\
\text { 2. Sekolah sudah } \\
\text { melakukan } \\
\text { pembiasaan nilai- } \\
\text { nilai utama karakter } \\
\text { 3. Sekolah sudah } \\
\text { mengembangkan } \\
\text { keunikan, kekhasan } \\
\text { dan keunggulan } \\
\text { sekolah (Branding) } \\
\text { 4. Sekolah sudah } \\
\text { mengembangkan } \\
\text { ekstrakurikuler } \\
\text { yang beragam } \\
\text { untuk } \\
\text { menumbuhkan } \\
\text { nilai-nilai karakter } \\
\text { 5. Sekolah sudah } \\
\text { mengembangkan } \\
\text { norma, peraturan } \\
\text { dan tradisi sekolah } \\
\text { yang aman dan } \\
\text { menyenangkan } \\
\text { 6. Dokumen sekolah } \\
\text { telah tertata dengan } \\
\text { baik berupa sof } \\
\text { sopy hard copy }\end{array}$ & $\begin{array}{l}\text { Hal-hal yang sudah baik : } \\
\text { 1. Sekolah sudah menjalin } \\
\text { kerjasama dengan } \\
\text { kepolisian, kesehatan, } \\
\text { instansi pemerintah, } \\
\text { perguruan tinggi, dan } \\
\text { swasta } \\
\text { 2. Sekolah sudah } \\
\text { melakukan kegiatan } \\
\text { pembiasaan nilai-nilai } \\
\text { karakter } \\
\text { 3. Sekolah sudah memiliki } \\
\text { keunikan, kekhasan dan } \\
\text { keunggulan dalam } \\
\text { bidang seni dan olahraga } \\
\text { 4. Sekolah sudah } \\
\text { mengembangkan } \\
\text { kegiatan ektrakurikuler } \\
\text { yang beragam untuk } \\
\text { menumbuhkan nilai-nilai } \\
\text { karakter } \\
\text { 5. Sekolah sudah memiliki } \\
\text { pedoman pengelolaan } \\
\text { sekolah yang lengkap } \\
\text { Dokumen sekolah telah } \\
\text { tertata dengan baik } \\
\text { berupa sof sopy hard } \\
\text { copy }\end{array}$ & $\begin{array}{l}\text { Pengembangan: } \\
\text { Hal-hal yang } \\
\text { sudah baik agar } \\
\text { terus } \\
\text { ditingkatkan dan } \\
\text { di kembangkan } \\
\text { Perbaikan : } \\
\text { Kepala sekolah } \\
\text { lebih } \\
\text { meningkatkan } \\
\text { disiplin dan } \\
\text { melakukan } \\
\text { pendekatan } \\
\text { kepada guru }\end{array}$ & $\begin{array}{l}\text { 1. Diskusi } \\
\text { 2. Konsultasi }\end{array}$ \\
\hline
\end{tabular}


7. Kehadiran guru pada saat upacara masih rendah

\author{
Hal yang belum baik : \\ Kehadiran guru pada saat \\ upacara bendera masih \\ rendah
}

Supervisi Penjaminan Mutu Pelaksanaan Proses Pembelajaran

\begin{tabular}{|c|c|c|c|}
\hline $\begin{array}{l}\text { Catatan Hasil } \\
\text { Pengamatan }\end{array}$ & Analisis Hasil Pengamatan & $\begin{array}{c}\text { Solusi/Tindak } \\
\text { Lanjut }\end{array}$ & $\begin{array}{c}\text { Aktifitas } \\
\text { Pendampingan }\end{array}$ \\
\hline $\begin{array}{l}\text { Aktifitas guru pada } \\
\text { saat membuka } \\
\text { pembelajaran; } \\
\text { 1. Mengajak siswa } \\
\text { berdo'a } \\
\text { 2. Mengabsen Siswa } \\
\text { 3. Melaksanakan } \\
\text { tindak lanjut dari } \\
\text { tugas sebelumnya. } \\
\text { 4. Melakukan } \\
\text { Apersepsi } \\
\text { 5. Menyampaikan } \\
\text { KD yang akan } \\
\text { dipelajari } \\
\text { 6. Membagi } \\
\text { Kelompok } \\
\text { Menjadi } 5 \\
\text { Kelompok }\end{array}$ & $\begin{array}{l}\text { Hal yang Baik; } \\
\text { 1. } \text { Mengajak siswa berdo'a } \\
\text { 2. Mengabsen Siswa } \\
\text { 3. } \text { Melaksanakan tindak } \\
\text { lanjut dari tugas } \\
\text { sebelumnya. } \\
\text { 4. } \begin{array}{l}\text { Menyampaikan KD yang } \\
\text { akan dipelajari }\end{array} \\
\text { 5. Membagi Kelompok } \\
\text { Menjadi } 5 \text { Kelompok } \\
\text { Hal yang Kurang Baik; } \\
\text { Melakukan Apersepsi }\end{array}$ & $\begin{array}{l}\text { Pengembangan; } \\
\text { Intensifkan } \\
\text { pertemuan di } \\
\text { MGMP } \\
\text { Perbaikan; } \\
\text { Melakukan } \\
\text { Apersepsi Perlu } \\
\text { perbaikan yaitu } \\
\text { dengan } \\
\text { membimbing dan } \\
\text { menjelaskan } \\
\text { guru tentang } \\
\text { pentingnya } \\
\text { dilakukan } \\
\text { apersepsi diawal } \\
\text { proses } \\
\text { pembelajaran }\end{array}$ & $\begin{array}{l}\text { Dengan cara } \\
\text { Diskusi dan } \\
\text { konsultasi } \\
\text { Memberikan } \\
\text { penjelasan, } \\
\text { pemahaman } \\
\text { dan contoh } \\
\text { Apersepsi } \\
\text { kepada guru } \\
\text { untuk dilakukan } \\
\text { pada setiap } \\
\text { kegiatan } \\
\text { pendahuluan } \\
\text { dalam proses } \\
\text { pembelajaran. }\end{array}$ \\
\hline $\begin{array}{l}\text { Sumber Belajar } \\
\text { 1. } \begin{array}{l}\text { Buku Matematika } \\
\text { siswa dalam } \\
\text { bentuk fotokofyan }\end{array} \\
\text { 2. } \begin{array}{l}\text { Guru Matematika } \\
\text { sebagai } \\
\text { Narasumber }\end{array}\end{array}$ & $\begin{array}{l}\text { Hal yang Baik; } \\
\text { Guru Matematika sebagai } \\
\text { Narasumber } \\
\text { Hal yang Kurang Baik; } \\
\text { Buku Matematika siswa } \\
\text { dalam bentuk Fotocofy }\end{array}$ & $\begin{array}{l}\text { Pengembangan; } \\
\text { Guru Matematika } \\
\text { terus } \\
\text { mempersiapkan } \\
\text { diri sebagai } \\
\text { narasumber } \\
\text { Perbaikan; } \\
\text { Buku } \\
\text { Matematiak yaitu } \\
\text { buku siswa } \\
\text { hendaknya dalam } \\
\text { bentuk paket . }\end{array}$ & $\begin{array}{l}\text { Kepala Sekolah } \\
\text { hendaknya } \\
\text { menggarkan } \\
\text { pada dana } \\
\text { sekolah untuk } \\
\text { lebih lancarnya } \\
\text { proses belajar } \\
\text { mengajar. }\end{array}$ \\
\hline $\begin{array}{l}\text { Kegiatan Guru Pada } \\
\text { saat Pembelajaran } \\
\text { 1. Kegiatan } \\
\text { Pendahuluan } \\
\text { a. Mengajak } \\
\quad \text { siswa berdo'a } \\
\text { b. Mengabsen }\end{array}$ & $\begin{array}{l}\text { Hal yang Baik; } \\
\text { 1. Kegiatan Pendahuluan } \\
\text { a. Mengajak siswa } \\
\text { berdo'a } \\
\text { b. Mengabsen Siswa } \\
\text { c. Melaksanakan } \\
\text { tindak lanjut dari }\end{array}$ & $\begin{array}{l}\text { Pengembangan; } \\
\text { Intensifkan } \\
\text { pertemuan di } \\
\text { MGMP } \\
\text { Perbaikan; } \\
\text { 1.Memberikan }\end{array}$ & $\begin{array}{l}\text { 1.Memberikan } \\
\text { penjelasan dan } \\
\text { bimbingan } \\
\text { kepada guru } \\
\text { tentang } \\
\text { pentingnya } \\
\text { Melakukan }\end{array}$ \\
\hline
\end{tabular}




\begin{tabular}{|c|c|c|c|}
\hline $\begin{array}{ll} & \text { Siswa } \\
\text { c. } & \text { Melaksanakan } \\
& \text { tindak lanjut } \\
& \text { dari tugas } \\
& \text { sebelumnya. } \\
\text { d. } & \text { Melakukan } \\
& \text { Apersepsi } \\
\text { e. } & \text { Menyampaika } \\
& \text { n KD yang } \\
& \text { akan dipelajari } \\
\text { f. } & \text { Membagi } \\
& \text { Kelompok } \\
& \text { Menjadi } 5 \\
& \text { Kelompok } \\
\text { 2. Kegiatan Inti } \\
\text { a. } & \text { Membagi LKS } \\
& \text { kepada } \\
& \text { masing-masing } \\
& \text { kelompok } \\
\text { b. } & \text { Menjelaskan } \\
\text { langkah- } \\
\text { langkan kerja } \\
\text { LKS didalam } \\
\text { diskusi } \\
\text { kelompok } \\
\text { c. } \text { Membimbing } \\
\text { siswa didalam } \\
\text { diskusi } \\
\text { delompok } \\
\text { d. } \text { Mengatur } \\
\text { jalannya } \\
\text { Presentasi } \\
\text { hasil kerja } \\
\text { kelompok } \\
\text { secara } \\
\text { bergiliran } \\
\text { 3. Kegiatan Penutup } \\
\text { a. } & \text { Membuat } \\
& \text { kesimpulan } \\
& \text { secara } \\
& \text { bersama-sama } \\
& \text { antar guru } \\
& \text { dengan siswa } \\
\text { } \text { Mefleksi } \\
\text { terhadap }\end{array}$ & $\begin{array}{ll} & \text { tugas sebelumnya. } \\
\text { d. } & \text { Menyampaikan KD } \\
& \text { yang akan dipelajari } \\
\text { e. } & \text { Membagi Kelompok } \\
& \text { Menjadi 5 } \\
& \text { Kelompok } \\
\text { 2. Kegiatan Inti } \\
\text { a. } \\
\text { Membagi LKS } \\
\text { kepada masing- } \\
\text { masing kelompok } \\
\text { b. } \text { Menjelaskan } \\
\text { langkah-langkan } \\
\text { kerja LKS didalam } \\
\text { diskusi kelompok } \\
\text { c. } \text { Membimbing siswa } \\
\text { didalam diskusi } \\
\text { delompok } \\
\text { Kegiatan Penutup } \\
\text { a. } \\
\text { Membuat } \\
\text { kesimpulan secara } \\
\text { bersama-sama antar } \\
\text { guru dengan siswa } \\
\text { b. } \text { Membuat Refleksi } \\
\text { terhadap materi } \\
\text { pembelajaran yang } \\
\text { sudah dilaksanakan } \\
\text { c. } \text { Memberikan } \\
\text { penilaian terhadap } \\
\text { ketercapaian tujuan } \\
\text { pembelajaran yang } \\
\text { dibuat pada RPP. } \\
\text { d. Memberikan tindak } \\
\text { lanjut berupa PR. }\end{array}$ & $\begin{array}{l}\text { penjelasan dan } \\
\text { bimbingan } \\
\text { kepada guru } \\
\text { tentang } \\
\text { pentingnya } \\
\text { Melakukan } \\
\text { Apersepsi } \\
\text { dipendahuluan } \\
\text { proses } \\
\text { pembelajaran } \\
\text { 2.Dengan diskusi } \\
\text { dan informasi } \\
\text { dan memberikan } \\
\text { contoh kepada } \\
\text { guru didalam } \\
\text { Memberikan } \\
\text { penilaian } \\
\text { terhadap } \\
\text { ketercapaian } \\
\text { tujuan } \\
\text { pembelajaran } \\
\text { yang dibuat pada } \\
\text { RPP. }\end{array}$ & $\begin{array}{l}\text { Apersepsi } \\
\text { dipendahuluan } \\
\text { proses } \\
\text { pembelajaran } \\
\text { 2.Dengan } \\
\text { diskusi dan } \\
\text { informasi dan } \\
\text { memberikan } \\
\text { contoh kepada } \\
\text { guru didalam } \\
\text { Memberikan } \\
\text { penilaian } \\
\text { terhadap } \\
\text { ketercapaian } \\
\text { tujuan } \\
\text { pembelajaran } \\
\text { yang dibuat } \\
\text { pada RPP. }\end{array}$ \\
\hline
\end{tabular}




\begin{tabular}{|c|c|c|c|}
\hline $\begin{array}{l}\text { pembelajaran } \\
\text { yang sudah } \\
\text { dilaksanakan } \\
\text { c. } \text { Memberikan } \\
\text { penilaian } \\
\text { terhadap } \\
\text { ketercapaian } \\
\text { tujuan } \\
\text { pembelajaran } \\
\text { yang dibuat } \\
\text { pada RPP. } \\
\text { d. } \text { Memberikan } \\
\text { tindak lanjut } \\
\text { berupa PR. }\end{array}$ & & & \\
\hline $\begin{array}{l}\text { Aktifitas penutupan } \\
\text { Pembelajaran } \\
\text { 1. Membuat } \\
\text { kesimpulan secara } \\
\text { bersama-sama } \\
\text { antar guru dengan } \\
\text { siswa } \\
\text { 2. Membuat Refleksi } \\
\text { terhadap materi } \\
\text { pembelajaran yang } \\
\text { sudah dilaksanakan } \\
\text { 3. Memberikan } \\
\text { penilaian terhadap } \\
\text { ketercapaian tujuan } \\
\text { pembelajaran yang } \\
\text { dibuat pada RPP. } \\
\text { 4. Memberikan tindak } \\
\text { lanjut berupa PR. }\end{array}$ & $\begin{array}{l}\text { Hal yang Baik; } \\
\text { 1. Membuat kesimpulan } \\
\text { secara bersama-sama } \\
\text { antar guru dengan siswa } \\
\text { 2. Membuat Refleksi } \\
\text { terhadap materi } \\
\text { pembelajaran yang sudah } \\
\text { dilaksanakan } \\
\text { 3. Memberikan tindak } \\
\text { lanjut berupa PR. } \\
\text { Memberikan } \\
\text { Hal yang Kurang Baik; } \\
\text { Penilaian terhadap } \\
\text { ketercapaian tujuan } \\
\text { pembelajaran yang dibuat } \\
\text { pada RPP. }\end{array}$ & $\begin{array}{l}\text { Pengembangan; } \\
\text { a. siswa dilatih } \\
\text { terus untuk } \\
\text { membuat } \\
\text { kesimpulan dan } \\
\text { refleksi } \\
\text { b..Memberikan } \\
\text { tindak lanjut } \\
\text { berupa PR. } \\
\text { Dibiasakan siswa } \\
\text { bekerja dirumah } \\
\text { Perbaikan; } \\
\text { Untuk } \\
\text { mengetahui } \\
\text { ketercapaian } \\
\text { tujuan } \\
\text { pembelajaran dan } \\
\text { ketuntasan } \\
\text { indicator } \\
\text { pencapaian } \\
\text { kompetensi guru } \\
\text { hendaknya } \\
\text { melakukan } \\
\text { penilaian diakhir } \\
\text { pembelajaran. }\end{array}$ & $\begin{array}{l}\text { Melalui diskusi } \\
\text { informasi } \\
\text { Disarankan dan } \\
\text { bimbing guru } \\
\text { untuk membuat } \\
\text { soal dan } \\
\text { melakukan } \\
\text { penilaian } \\
\text { diakhir } \\
\text { pembelajaran } \\
\text { guna untuk } \\
\text { mengetahui } \\
\text { ketercapaian } \\
\text { tujuan } \\
\text { pembelajaran } \\
\text { dan ketuntasan } \\
\text { indicator. }\end{array}$ \\
\hline
\end{tabular}

Supervisi Dampak Penjaminan Mutu Pada Peningkatan Kompetensi Lulusan

\begin{tabular}{|c|c|c|c|}
\hline $\begin{array}{c}\text { Catatan Hasil } \\
\text { Pengamatan }\end{array}$ & $\begin{array}{c}\text { Analisis Hasil } \\
\text { Pengamatan }\end{array}$ & $\begin{array}{c}\text { Solusi/ Tindak } \\
\text { Lanjut }\end{array}$ & $\begin{array}{c}\text { Aktivitas } \\
\text { Pendampingan }\end{array}$ \\
\hline
\end{tabular}




\begin{tabular}{|c|c|c|c|}
\hline $\begin{array}{l}\text { Kompet } \\
\text { Sikap } \\
\text { 1. Siswa } \\
\text { menit }\end{array}$ & $\begin{array}{l}\text { Hal yang sudah } \\
\text { baik: } \\
\text { 1. Siswa setiap } 30 \\
\text { menit sebelum } \\
\text { pelajaran dimulai } \\
\text { dilaksanakan } \\
\text { tadarus (muslim) } \\
\text { dan baca kitab } \\
\text { (non muslim). } \\
\text { 2. Siswa ada yang } \\
\text { piket jam 06.15 } \\
\text { Wita untuk } \\
\text { menyambut } \\
\text { kedatangan } \\
\text { temannya } \\
\text { Hal yang belum } \\
\text { baik: } \\
\text { 1. Siswa belum } \\
\text { memiliki pojok } \\
\text { baca kelas yang } \\
\text { ada di kelas } \\
\text { masing-masing, } \\
\text { 2. Siswa jarang } \\
\text { mengunjungi } \\
\text { perpustakaan } \\
\text { 3. Siswa kurang } \\
\text { peduli terhadap } \\
\text { lingkungan } \\
\text { sekolah } \\
\text { 4. Siswa belum } \\
\text { terbentuk budaya } \\
\text { membaca }\end{array}$ & $\begin{array}{l}\text { Pengembangan: } \\
\text { Sikap siswa yang } \\
\text { sudah baik diharapkan } \\
\text { untuk ditingkatakan } \\
\text { dan dikembangkan } \\
\text { Perbaikan: } \\
\text { 1. Dibuat pojok baca } \\
\text { dikelas. } \\
\text { 2. Memberdayakan } \\
\text { perpustakaan } \\
\text { sekolah } \\
\text { 3. Dibuatkan slogan } \\
\text { yang menyangkut } \\
\text { ttg kebersihan } \\
\text { 4. Guru } \\
\text { memperbanyak } \\
\text { tugas membaca bagi } \\
\text { siswa }\end{array}$ & $\begin{array}{l}\text { Solusi dan } \\
\text { pendampingan yang } \\
\text { dilakukan: } \\
\text { Melakukan kegiatan } \\
\text { diskusi dan konsultasi } \\
\text { untuk pengembangan } \\
\text { sikap,keterampilan dan } \\
\text { pengetahuan siswa } \\
\text { Kendala: } \\
\text { Sekolah kesulitan } \\
\text { dalam penganggaran } \\
\text { biaya. }\end{array}$ \\
\hline $\begin{array}{l}\text { Kompetensi } \\
\text { Keterampilan } \\
\text { Siswa sudah } \\
\text { mampu } \\
\text { membaca al- } \\
\text { qur'an } \\
\text { Siswa belum } \\
\text { bisa membuat } \\
\text { tulisan di } \\
\text { mading sekolah }\end{array}$ & $\begin{array}{l}\text { Hal yang sudah } \\
\text { baik; } \\
\text { Siswa sudah mampu } \\
\text { membaca al-qur'an } \\
\text { Hal yang belum } \\
\text { baik; } \\
\text { Siswa belum ada } \\
\text { membuat tulisan di } \\
\text { madding sekolah }\end{array}$ & $\begin{array}{l}\text { Pengembangan : } \\
\text { Kemampuan membaca } \\
\text { alqur'an dapat } \\
\text { ditingkatkan ke } \\
\text { hafalan } \\
\text { Perbaikan : } \\
\text { Siswa didorong untuk } \\
\text { membuat tulisan untuk } \\
\text { madding sesuai } \\
\text { kemampuan }\end{array}$ & $\begin{array}{l}\text { Solusi dan } \\
\text { pendampingan yang } \\
\text { dilakukan: } \\
\text { Melakukan kegiatan } \\
\text { diskusi dan konsultasi } \\
\text { untuk pengembangan } \\
\text { sikap,keterampilan dan } \\
\text { pengetahuan siswa }\end{array}$ \\
\hline $\begin{array}{l}\text { Kompetensi } \\
\text { Pengetahuan } \\
\text { 1. Siswa sudah } \\
\text { mampu } \\
\end{array}$ & $\begin{array}{l}\text { Hal yang sudah baik } \\
\text { Siswa sudah mampu } \\
\text { menyusun laporan } \\
\text { dan menulis KTI } \\
\end{array}$ & $\begin{array}{l}\text { Pengembangan : } \\
\text { Tingkatkan } \\
\text { kemampuan siswa } \\
\text { dalam menyusn } \\
\end{array}$ & $\begin{array}{l}\text { Solusi dan } \\
\text { pendampingan yang } \\
\text { dilakukan: } \\
\text { Melakukan kegiatan }\end{array}$ \\
\hline
\end{tabular}


menyusun

laporan dan

menulis KTI

2. Siswa Belum

mampu meraih

prestasi

akademik

(olimpiade) laporan dan menulis

KTI

Hal yang belum

baik;

Siswa Belum mampu

meraih prestasi

akademik (olimpiade)
Perbaikan :

Membuatkan program

pembinaan dan

mecarikan guru/dosen

pembimbing

\section{Kesimpulan}

Kesimpulan yang diperoleh dari penelitian ini antara lain adalah; (1) Pemahaman tentang Standar Mutu di SMKN 1 Pujut sudah baik ditandai dengan hasil raport mutu sudah menuju SNP 4 dengan nilai capaian 5,74; (2) Penerapan Sistem Penjaminan Mutu Internal (SPMI) di SMKN 1 Pujut sudah terlaksana dengan baik mulai dari pemetaan mutu, perencanaan rogram, pelaksanaan, dan evaluasi; (3) Implementasi K13 di SMKN 1 Pujut sudah sesuai dengan ketentuan; (4) Penguatan Pendidikan Karakter (PPK) di SMKN 1 Pujut sudah berjalan dengan baik ditandai dengan hasil raport PPK mencapai 6.48 menuju SNP 4.; (5) Gerakan literasi sekolah (GLS) di SMKN 1 Pujut sudah mencapai SNP dengan nilai 6.69; dan (6) Pelaksanaan UKS di SMKN 1 Pujut mencapai 5.8 menuju SNP 4.

\section{Saran}

Adapun saran yang dapat disampaikan berdasarkan hasil penelitian ini adalah; agar sekolah dapat menjaga dan terus meningkatkan mutu yang telah dicapai sehingga dapat dijadikan contoh atau best practice bagi sekolah lainnya.

\section{Daftar Pustaka}

Kementrian Pendidikan dan Kebudayaan Direktorat Jendral Manajemen Pendidikan Dasar dan Menengah. (2017). Pengumulan Data Peta Mutu Satuan Pendidikan.

KementriaPendidikan dan Kebudayaan Direktorat Jendral Manajemen Pendidikan Dasar dan Menengah. (2017). Indikator Mutu dalam Penjaminan Mutu Pendidikan Dasar dan Menengah.

Kementrian Pendidikan dan Kebudayaan Direktorat Jendral Manajemen Pendidikan Dasar dan Menengah. (2017) Petunjuk Teknis Pengembangan Peta Mutu.

Kementrian Pendidikan dan Kebudayaan Direktorat Jendral Manajemen Pendidikan Dasar dan Menengah. (2017). Perangkat Instrumen Pemetaan Mutu Pendidikan Dasar dan Menengah Tingkat Sekolah Mengah Atas.

Kementrian Pendidikan dan Kebudayaan Direktorat Jendral Manajemen Pendidikan Dasar dan Menengah. (2019). Petunjuk Pelaksanaan Supervisi Mutu Pendidikan.

Kementrian Pendidikan dan Kebudayaan Direktorat Jendral Manajemen Pendidikan Dasar dan Menengah. (2017). Gerakan Literasi Nasional Materi Pendukung Literasi Baca Tulis.

Kementrian Pendidikan dan Kebudayaan Direktorat Jendral Manajemen Pendidikan Dasar dan Menengah. (2018). Konsep dan Pedoman Penguatan Pendidikan Karakter Tingkat Sekolah Dasar dan Sekolah Menengah Pertama.

Kementrian Pendidikan dan Kebudayaan Direktorat Jendral Manajemen Pendidikan Dasar dan Menengah. (2018). Modul Pelatihan Penguatan Pendidikan Karakter bagi Pengawas. 
Kementrian Pendidikan dan Kebudayaan Direktorat Jendral Guru dan Tenaga Kependidikan. (2018). Modul Manajemen Implementasi Kurikulum 2013 Jenjang SMA/SMK.

Prayoga, S. (2020). Pendampingan Implementasi SPMI di Sekolah Model dan Sekolah Imbas SMA Kota Mataram 2019. Jurnal Paedagogy, 7(1), 25-34. doi:https://doi.org/10.33394/jp.v7i1.2512

Purnamaraya, S. (2019). Upaya Meningkatkan Kompetensi Guru Kelas dalam Proses Pembelajaran Berdasarkan Kurikulum 2013 Melalui Supervisi Akademik di SD $\begin{array}{llll}\text { Negeri } & 45 & \text { Mataram. Jurnal Paedagogy, } & 6(2),\end{array}$ doi:https://doi.org/10.33394/jp.v6i2.2531

Rusdi, T. (2020). Upaya Peningkatan Mutu Guru Melalui Pembimbingan Penyusunan Penelitian Tindakan Kelas di MIN 2 Kota Mataram. Jurnal Paedagogy, 7(3), 216225. doi:https://doi.org/10.33394/jp.v7i3.2731

Rusmiarsi, R. (2017). Meningkatkan Kompetensi Guru dalam Proses Pembelajaran Berdasarkan Kurikulum 2013 Melalui Supervisi Akademik di SD Negeri 40 Ampenan. Jurnal Kependidikan: Jurnal Hasil Penelitian dan Kajian Kepustakaan di Bidang Pendidikan, Pengajaran dan Pembelajaran, 3(2). doi:https://doi.org/10.33394/jk.v3i2.680

Suginam, A. (2019). Upaya Meningkatkan Kompetensi Guru Kelas dalam Proses Pembelajaran Melalui Supervisi Akademik di SD Negeri 4 Mataram. Jurnal Paedagogy, 6(2), 41-48. doi:https://doi.org/10.33394/jp.v6i2.2530

Supatni, P. (2017). Mengefektifkan Pelaksanaan Supervisi Akademik dalam Upaya Meningkatkan Kompetensi Guru Kelas dalam Proses Pembelajaran di SDN 36 Ampenan. Jurnal Kependidikan: Jurnal Hasil Penelitian dan Kajian Kepustakaan di Bidang Pendidikan, Pengajaran dan Pembelajaran, 3(1). doi:https://doi.org/10.33394/jk.v3i1.473

Yuniati, S., \& Prayoga, S. (2019). Pengaruh Manajemen Perencanaan Pembelajaran Terhadap Kinerja Guru SMA Negeri di Kota Mataram. Jurnal Kependidikan: Jurnal Hasil Penelitian dan Kajian Kepustakaan di Bidang Pendidikan, Pengajaran dan Pembelajaran, 5(2), 133-140. doi:https://doi.org/10.33394/jk.v5i2.1811 